\title{
LA RURALIDAD EN LA COTIDIANIDAD ESCOLAR COLOMBIANA Historia de vida de la maestra rural boyacense. 1948-1974 ${ }^{1}$
}

\author{
Diana Elvira Soto Arango ${ }^{2}$ \\ Universidad Pedagógica y Tecnológica de Colombia- Colombia \\ Grupo de Investigación HISULA \\ dianaelvirasoto@gmail.com
}

Recepción: 21/02/2012

Evaluación: $12 / 03 / 2012$

Aceptación: 29/05/2012

Artículo de Reflexión

doi: 10,9757

\section{RESUMEN}

La investigación analiza el período de de desplazados con el impacto que sobre ellos violencia política de mediados del siglo XX, en Colombia, a través de la historia de vida y cotidianidad escolar de una maestra de escuela rural, de filiación política liberal, desplazada y perseguida.

El método se centra en la historia social, desde la perspectiva socio-política y de las mentalidades, que incluye los imaginarios colectivos y la vida cotidiana. La historia de vida, proporcionó los procedimientos, clasificación y organización de la información. La biografía de la maestra y la historia de su familia permitió analizar el cambio de la estructura familiar y el comportamiento de la misma en la categoría ejerció la violencia política y los cambios socioeducativos. Las estrategias utilizadas se centraron en las fuentes primarias. Se concluyo que la maestra, desarrollo un peculiar adaptacionismo socio-cultural. El sentido histórico que se logró en la investigación invita a re-pensar en los mecanismos y políticas para desplazados de la violencia actual en Colombia donde la educación tiene la última palabra en el cambio de estructuras mentales hacia una sociedad del conocimiento.

Palabras clave: Revista Historia de la Educación Latinaomericana, violencia, ruralidad, urbano, maestra, desplazado.

Este trabajo hace parte del proyecto marco "La universidad en la capacitación de maestras rurales en Colombia y Guatemala", bajo la dirección de la Dra. Diana Soto Arango, Dr. Justo Cuño Bonito, Dr. Óscar Hugo López. Avalado por la Universidad Pedagógica y Tecnológica de Colombia con el Código SGI: 980 por la Dirección de Investigaciones de esta Institución. Este se desarrolla en convenio con la Universidad Pablo de Olavide- España, y Universidad de San Carlos -Guatemala con el Código SGI: 1034.

2 Profesora titular de la Universidad Pedagógica y Tecnológica de Colombia máxima categoría. Posdoctorado realizado en el Consejo Superior de Investigaciones Científicas de España del 12 de Julio de 1993 a diciembre de 1995. Doctora en Ciencias de la Educación en la UNED de España, 1987. Organizó en 1996 y fue la primera Directora del Doctorado en Ciencias de la Educación de RUDECOLOMBIA. Organizó en 1992 la Sociedad de Historia de la Educación Latinoamericana y es la Directora de los Grupos de Investigación: Historia y Prospectiva de la Universidad Latinoamericana-HISULA y la Ilustración en América Colonial -ILAC, reconocidos en COLCIENCIAS, Categoría A1. Artículo vinculado al proyecto de investigación la Universidad en la capacitación de maestras rurales en Colombia y Guatemala SGI 1034 y proyecto Historias de vida. Maestras rurales de mediados del siglo XX y XXI en la zona cundiboyacense SGI 980 del grupo de investigación HISULA - UPTC. 


\section{THE DAILY LIFE OF A RURAL COLOMBIAN TEACHER}

Life history of the boyacense rural educator 1948-1974

\section{ABSTRACT}

The research analyzes the period of political violence in the middle of the twentieth century in Colombia, through the story of a teacher's life and daily life from a rural school, with a liberal political affiliation, displaced and persecuted.

The method focuses on the social history from a socio-political and mindset perspective that includes the collective imaginaries and everyday life. The story of life provided the procedures, classification and organization of the information. The biography of the teacher and the story of her family made it possible to analyze the change in the family structure and its behavior in the category of displaced persons with the impact that political violence and socio-educational changes had on them. The strategies used were focused on the primary sources. It was concluded that the teacher, developed a peculiar sociocultural adaptationism. The historical sense that was achieved in the research invites to rethink about the mechanisms and policies for displaced persons by the current violence in Colombia, where education has the last word in the change of mental structures toward the knowledge society.

Key words: History of Latin American Education Magazine, violence, rurality, urban, teacher, displaced person.

\section{A RURALIDADE NO COTIDIANO ESCOLAR COLOMBIANO HISTÓRIA DE VIDA DA PROFESSORA RURAL BOYACENSE. 1948-1974}

\section{RESUMO}

A pesquisa analisa o período de violência política em meados do século XX, na Colômbia, através da história da vida cotidiana e da escola em um professor de escola rural, de filiação política liberal, deslocados e perseguidos.

O método centra-se na história social, a partir das atitudes sócio-políticas e, inclusive o imaginário coletivo e da vida cotidiana. A história de vida, desde os procedimentos, classificação e organização de informações. Biografia do professor e da história de sua família permitiram analisar a mudança na estrutura familiar e comportamento do mesmo na categoria de deslocados com o impacto sobre eles exercido violência política e sócio-educacional. As estratégias utilizadas são focados em fontes primárias. Concluiuse que o professor, o desenvolvimento de um adaptacionismo sócio-cultural peculiar. $\mathrm{O}$ sentido histórico foi alcançado em pesquisa convida a repensar os mecanismos e políticas para a violência atual deslocados na Colômbia, onde a educação tem a palavra final na mudança de mentalidades no sentido de uma sociedade do conhecimento.

Palavras-chave: Revista Historia da Educação Latino-americana, violência, ruralidade, urbano, professora, deslocado.

\section{INTRODUCCIÓN}

La investigación se centró en analizar la historia de vida de una maestra dentro de los contextos de lo rural y lo urbano atravesados por un periodo histórico de violencia en Colombia, en los años de 1948 que va transformándose con el denominado Frente Nacional, (1958-1974), en la región cundi-boyacense. Desde esta perspectiva, el estudio se enmarcó en una familia liberal, desplazada de la población de Yacopí, donde se destacó la historia de vida de una integrante mujer que se formó dentro de los parámetros que le establecía la función en la sociedad, de relegarla al ámbito de lo doméstico, para ser una "buena ama de casa" dentro de la denominada profesión hogar. Su familia se caracterizó 
por la tradición a la obediencia patriarcal. Sin embargo, el hecho político del "bogotonazo" de 1948 con las consecuencias de los desplazamientos le lleva, a la mujer del estudio, al desempeño docente en Boyacá como maestra rural en contextos vulnerables de exclusión socio-educativa y persecución política. Se destaca el impacto de su desempeño docente en los espacios rurales. Acentuamos, que son numerosas las investigaciones sobre la escuela rural ${ }^{3}$ en Latinoamérica ${ }^{4}$ y sobre la mujer en Colombia ${ }^{5}$. Respecto a las mujeres se orientan en su mayoría "sobre el papel que desempeñan en el hogar, la sociedad, el trabajo, la cultura y la política" ${ }^{\prime 6}$ pero son muy escasas sobre la maestra rural en este país?

El hilo conductor de este estudio se establece desde la diferencia de lo urbano y lo rural, como espacios que determinan comportamientos culturales, políticos, religiosos, y económicos, sustentados en empresas de economía rural familiar. La historia de vida y familiar es captada, descrita e interpretada en un contexto socio-político, que enfatiza en el cambio de costumbres y de estructuras mentales con una capacidad de adaptación a nuevos espacios político-locales, que es uno de los objetivos fundamentales de este estudio.

3 Véase estudios sobre la ruralidad y la escuela rural en: Ortega de Alarcón, "La Educación Rural y la Educación Fundamental en Colombia. Centro Regional de Educación Fundamental para la América Latina". (1955 http: //www.crefal.edu.mx/biblioteca_digital/coleccion_crefal/tesis/alarcon_ortega. de. 16 de marzo de 2012; Ligia Angulo H, David Morera H, y Nancy Torres V, "Modelo y práctica pedagógica en la escuela rural unidocente y multigrado centroamericana: condiciones, limitaciones y potencialidades", en Revista Centroamericana de Educación. http:/ / mnnn.ceducar:info/OJS. (16 de marzo de 2012); María Ramírez G y Juana Téllez C, "La educación primaria y secundaria en Colombia en el siglo XX”. http://www. banrep.gov.co/docum/ftp/borra379.pdf; Josué Ramón Suárez, "Historia y sentido de la escuela rural. De la escuela unitaria a la educación media. 1960-2005" (Tesis Doctoral en Doctorado en Ciencias de la Educación, Universidad Pedagógica y Tecnológica de Colombia-RUDECOLOMBIA, 2006).

Alba Nidia Triana, "Historia de la educación rural en Colombia. 1946-1994" (Tesis Doctoral. Doctorado en Ciencias de la Educación, Universidad Pedagógica y Tecnológica de Colombia-RUDECOLOMBIA, 2010).

4 Entre otras, M. TEUBAL, "Globalización y nueva Ruralidad en América Latina”, en Una Nueva Ruralidad en América Latina (Bogotá: Uniandes, 2005); Christopher Wulf, "¿Cómo adquiere sentido la Escuela? Encuentros Pedagógicos Transculturales" (Medellín: Universidad de Antioquia, Facultad de Educación, 2001).

5 Véase una amplia bibliografía reseñada en la tesis de Ana Hamon, Ingreso de la mujer docente a la UPTC 1961-1980 (Tesis Doctoral en Doctorado en Ciencias de la Educación, Universidad Pedagógica y Tecnológica de Colombia-RUDECOLOMBIA, 2010); Mabel Bellucci, MUJERES en la educación: género y docencia en Argentina: 1870-1930. (Buenos Aires, 1997); Guillermo Hernández de Alba, "Galería de ilustres educadoras colombianas [manuscrito]: en 1. Colegio de La Merced. (Bogotá, 1900); [Goodson Ivor, Historias de vida del Profesorado" (Barcelona: Octaedro editorial, 2004)]; Elizabeth King, "Educating girls and women: investment in development" (Washington: World Bank, 1990); Gabriela Mistral, "Nubes blancas (poesias) y la oración de la maestro" (Barcelona: Editorial B. Bauza, 1941); P Woods, "Life Histories and Teacher knowledges, en educating teachers; changing the nature of pedagogical knowledges" (Londres, Filadelfia y New York, FALMER, 1987).

6 Hamon, "Ingreso de la mujer", 15.

7 Excepto estos dos libros que hemos localizado de Myriam Stella Ferro, "Mi vida. Historia de la vida de una maestra rural colombiana" (Bogotá: Editorial Guadalupe, 1978); Liria Pérez Peláez, "La educadora de primaria: auto percepción de sus roles como maestra y mijer" (Medellín: Universidad de Antioquia-Facultad de Educación, 1990), 98. 
Por lo señalado anteriormente, la pregunta desde la cual abordamos la historia de vida de la maestra se centra en: ¿Cuáles fueron los factores familiares y cambios de lo urbano y lo rural, que incidieron en la capacidad de adaptación y de liderazgo de la maestra en la zona rural de Boyacá, atravesado por el impacto de la violencia política de 1948 a 1974?.

El método de la historia social, desde la perspectiva socio-política y de las mentalidades, que incluye los imaginarios colectivos y la historia de la vida cotidiana, desde lo público, sustenta el marco teórico de la investigación. Así mismo, el estudio de lo cotidiano de la maestra, junto al análisis de los espacios físicos de las casas de las familias urbanas y rurales, nos indica comportamientos culturales y sociales que se relacionan con la autoridad.

Cabe anotar que la metodología de la historia de vida ${ }^{8}$ nos proporcionó los procedimientos, clasificación y organización de la información. La construcción de la biografía se estableció partiendo de su vida personal. Asimismo, podríamos añadir que el imaginario social ${ }^{2}$, se convirtió en una categoría de análisis fundamental. Más aún, el etnoconocimiento de la recuperación de saberes de lo rural y de lo urbano, que la maestra integró, consideramos que fue un elemento que le permitió conocer los factores que favorecieron y dificultaron su adaptación y el liderazgo en su desempeño como educadora. El estudio, podemos considerarlo dentro de la tendencia historiográfica de re-significar el rol de la mujer y en este caso de una maestra en el contexto rural en el período de estudio en Colombia.

Las variables del estudio se centraron en el análisis comparativo de la primera etapa, de la experiencia urbana, hasta los 23 años de edad en Cundinamarca, con la segunda etapa, de la experiencia rural en el desempeño docente de maestra en la zona campesina de Boyacá, hasta los 54 años que finaliza su trabajo en este Departamento. Debemos indicar que, la ruralidad y lo urbano, en la historia

8 La historia de vida, se focaliza la experiencia personal de un informante de este modo tiene el carácter de una historia oral con enfoque biográfico. V. Córdoba, "Historias de Vida. Una metodología alternativa para Ciencias Sociales" (Caracas: Fondo Editorial Tropikos, 1993), 87; G Rocca M. Magrassi, "Historia de vida." (Buenos Aires, Centro Editor de América Latina ,1979): Domingo Bolívar y Fernández, "La Investigación Biográfica Narrativa en Educación. Enfoque y Metodología" (Madrid: Editorial La Muralla, S.A, 2001).

9 El imaginario social es un concepto creado por el filósofo griego Cornelius Castoriadis, usado habitualmente en ciencias sociales para designar las representaciones sociales encarnadas en sus instituciones. Daniel Cabrera, indica que "el imaginario se constituye en una categoría de interpretación para las creencias e imágenes colectivas. Se convierte en el espacio de "construcción de identidades colectivas a la manera de verse, imaginarse y pensarse como Imaginario social, comunicación e identidad colectiva. Universidad de Navarra. Consultado en Wikipedia, 20 de octubre del 2010. Benedict Anderson, "Imagened Communities" (London: Verso, 1983); Cornelius Castoriadis, "La institución imaginaria de la Sociedad", en El mundo Fragmentado, (Barcelona, Buenos Aires: Tusquets Editores, 1990), Gilbert Durand, "Lo imaginario" (Barcelona: Ediciones del Bronce, 1994); Paul du Gay, "Cuestiones de identidad cultural" (Buenos Aires: Amorrortu, 1996). 
de vida de la maestra, corresponde a la variable de análisis, donde se estudian: los espacios físicos de las construcciones; el alimento, el vestido, mitos y leyendas, estructura familiar, el colegio y la escuela, los viajes, el comercio, la iglesia y las fiestas. Las estrategias utilizadas se centraron en las fuentes primarias de información, a través de la historia oral que se concretó en las entrevistas ${ }^{10}$ a la maestra, hija, nietos, sobrinos, familiares, amigos y exalumnos. Los archivos familiares de documentos personales, junto con la iconografía centrada en las fotos, folletos, diplomas y legislación. El sentido histórico que se logró en la investigación invita a repensar los procesos de adaptación y transformaciones sociales, económicas y culturales que afectaron a un grupo de familias desplazadas por la violencia.

Se concluye, en primera instancia, que en el período de estudio, la ruralidad en costumbres de lo cotidiano, alimentación y formas de construcción presentan cambios en los medios rurales por la influencia de lo urbano. Asimismo, se exhiben transformaciones en el vestido y una apertura respecto a la función social de la mujer. Segundo, el desplazamiento forzado trajo cambios en las relaciones socio-económicas en los contextos rurales y urbanos, donde la educación fue el principal elemento de superación socio-económica, en el caso de la familia estudiada. Tercero, las secuelas de la violencia estuvieron presentes en la maestra, quien con una gran capacidad de adaptación, desarrolló actividades socio-educativas, en las escuelas rurales. Cuarto, las políticas del Estado no transformaron en este período la escuela unitaria en el sector rural.

\section{Lo urbano y lo rural, contraste en historia de vida de la maestra}

El primer análisis se centra en indagar comparativamente, en el tiempo, lo rural ${ }^{11}$ y lo urbano, con la mirada transversal de la violencia política, de los

10 Citado por "Las memorias y testimonios ofrecidos no significan rehacer cada evento tal cual ocurrió, sino que son producto de los relatos y recuerdos que se han de comunicar de manera oral y/o presentando evidencia no de los hechos como tal, sino de situaciones que nos aproximarán al mismo" José Viloria Asención, "La educación y la escuela en Venezuela" en Una Historia de Vida, eds. Gilberto Picón Medina (Caracas: Fondo Editorial de la Universidad Pedagógica Experimental Libertador, 1997), 25.

11 Lo rural lo asumimos con el concepto del Primer Seminario de Escuelas Normales Rurales para Centro América y Panamá en Tegucigalpa en septiembre de 1957 "La ruralidad es un hecho complejo determinado por factores de índole geográfico, económico, social y cultural que, como ambiente natural, definen las formas de vida de grupos de población de baja densidad. Se caracteriza por el contacto directo del hombre con la naturaleza, en el aprovechamiento de sus recursos, de preferencia en las ocupaciones agropecuarias; la dispersión de la población o su concentración en pequeñas agrupaciones, la reducida aplicación de técnicas científicas en el trabajo, la frecuente insuficiencia de servicios públicos, el predominio de contactos personales en las relaciones humanas; el relativo aislamiento de los grupos y la vigencia predominante de las tradiciones y formas peculiares de la cultura", Véase en: Alba Nidia Triana, "La educación rural en Colombia: de la contrarreforma conservadora al Frente Nacional' (Tunja: Universidad Pedagógica y Tecnológica de Colombia-RUDECOLOMBIA, 2008), 22-23. 
años cincuenta, en Colombia, a través de historias de vida entretejidas en la historia familiar en medio de realidades e imaginarios, ${ }^{12}$ que transformaron las estructuras mentales, sociales culturales y educativas y que se plasman en la comparación en el desempeño docente de la maestra rural de nuestro estudio. El estudio se centra en el período de 1948 a $1974^{13}$.

Iniciamos el periodo de estudio con el denominado "bogotazo", que se ocasionó por el asesinato del líder político liberal Jorge Eliécer Gaitán, el 9 de abril de 1948, durante el gobierno de Mariano Ospina Pérez ${ }^{14}$ que cambia la vida de la población colombiana y en especial la de algunos pueblos, como el de Yacopi, Cundinamarca, que fue quemado y bombardeado por tercera vez en su historia, el 6 de diciembre del año 1952. Finalizamos el período de estudio en 1974 cuando terminó el pacto del Frente Nacional. Sin embargo, se hace necesario conocer algunos elementos hasta 1980 cuando la maestra concluye su período de 27 años de vida en Boyacá y de estos, 25 en el magisterio rural.

Hay que destacar que en el período de 1950 a 1970 la población rural se reduce de $59 \%$ a $42 \%$ por el fenómeno del desplazamiento forzado, de los habitantes de los campos a los pueblos y de los pueblos a las ciudades. Se trataba, según los entrevistados, de salvar la vida y de lograr conseguir condiciones dignas para vivir ${ }^{15}$. Aún hay otra consideración es que la población en Colombia se duplica en estos veinte años. Se pasa de una población total de 12.568.000 en 1950, a una población de 22.560 .539 en el año $1970^{16}$. Pero destacamos que en el año 1950, teniendo el 59\% de la población en el sector rural, sólo se tenía un 30\% de escuelas rurales, con el $7,5 \%$ de matrícula ${ }^{17}$, y el $66 \%$ de los docentes sin título ${ }^{18}$. Lo relevante es que se establecen cambios significativos entre lo rural y lo urbano, en el período de estudio, especialmente, la transformación en la propiedad, la vinculación a un sistema educativo que se encamina hacia nuevas formas de producción

\footnotetext{
12 Nosotros asumimos en este estudio el imaginario social como la categoría de análisis para reconocer un colectivo, en su ideología política, en un lugar determinado y el imaginario individual como se percibe la maestra en ese contexto local del imaginario político colectivo.

13 El período de estudio se enmarca en hechos políticos.

14 Gobierna el país Mariano Ospina Pérez de 1946 a 1950.

15 En 1951 el analfabetismo era del 37,7\%. En el año 1978 pasa al 16.8\%, en el año 2000 a 8,1\%. Fuente: Censos de población 1938-1973, Encuesta Nacional de Hogares 1981, 50 años de Estadísticas Educativas, DANE. Cálculos de la Misión Social (Colombia: Departamento Nacional de Planeación, 1981); Proyección 2003; Cálculos GRECO; Banco de la República.

16 Contrasta con la población en el año 2010 que correspondía a 49.665,343 con un 22\% de población rural. http://www.eclac.org/publicaciones/xml/4/7394/LCG2140_Tabgenerales.pdf (24 de marzo del 2011).

17 En el año 1976 se aumenta al 17\%. La matrícula en las escuelas rurales.

18 María Teresa Ramírez G y Juana Téllez C, "La educación primaria y secundaria en Colombia en el siglo XX" (Colombia: 2006), 32.
} 
industrial. Pero, en especial la influencia de los medios de comunicación y la tendencia hacia la sociedad del consumo ${ }^{19}$.

La anterior descripción de población y matrícula en escuelas rurales representan el entorno histórico del desempeño docente de la maestra desplazada. Hay sin embargo que mencionar el imaginario que manejan los entrevistados sobre lo rural y lo urbano. En este sentido, debemos indicar que el término que utilizan los entrevistados es de "campo", caserío, pueblo y ciudad. En el primer concepto, el campo, significa para ellos que se vivía fuera del "casco urbano" y sus habitantes tenían condiciones de vida diferentes a las del pueblo. En palabras de la maestra era "el atraso, no había cultura y sí muchas necesidades" 20 . Esta es una apreciación que manifiesta ella ahora, después de haber vivido su experiencia de maestra rural, pero que es diferente a la que expresa del pasado cuando el campo era el lugar del "paseo" y de estar en contacto con la naturaleza, de la región de Yacopí. Pero, bien sabemos que la característica fundamental del campo está dada por la tenencia de la tierra que es la que va a determinar las relaciones sociales y de autoridad. Es así, que son muy diferentes las relaciones socio-económicas en una vereda con latifundio ganadera que otra de minifundio con pequeña producción del "pan coger" 21 . En Yacopí, lugar de origen de la maestra, se intercalaban las dos formas de tenencia de la tierra. Esta es una región en medio de montañas, con una altura propicia para el cultivo del café y con abundante agua y pasto para la ganadería. La finca del padre de Amparo estaba dedicada a la ganadería y se ubicaba en la vereda de Alto Seco, a siete horas a caballo de Yacopí. Comentan los entrevistados que el mayordomo les enviaba yuca, plátano y frutas pero ni Amparo, ni sus hermanas viajaron a este lugar.

Hasta ahora lo esencial es que el período de los años cincuenta en Colombia tenía una marcada ruralidad. El mayor porcentaje de la población vivía en condiciones de exclusión socio-educativa y con el "bogotazo" se dio una emigración por diferentes sectores del país. Esta población emigrante se encontró con unas condiciones de vida diferente en la ciudad. En el caso de la familia de la maestra, que emigró a Bogotá, consideramos que logró la adaptación porque las relaciones familiares se cohesionaron entorno a lo que denominaron "salir adelante".

19 Pilar Gonzalbo, "Vida cotidiana" (México: Colegio de México, 2006), 80.

20 Entrevista a la maestra Arango, Amparo, Fusagasugá, 20 de mayo del 2012.

21 Término que utilizan para indicar el cultivo básico de sostenimiento de una familia. En algunos casos, con un pequeño excedente para la venta. 


\section{De la casa de bahareque con techo de palmicha a la casa de adobe y ladrillo con techo-de teja de zinc}

En general, se está de acuerdo, que el campo representa exclusión y marginalidad, manifiesta en: falta de alcantarillado, acueducto, servicios sanitarios, electricidad, teléfono, servicios de salud, caminos intransitables. Hay que añadir la precariedad de la construcción de sus casas, vestido y acceso a los medios educativos. Sin embargo, es notoria la diferencia entre una casa rural de un campesino del minifundio y una del patrón, cuando éste habita con su familia en el campo. Como lo indica la historiadora Pilar Gonzalbo, "la casa es el ámbito de la intimidad; jurídicamente es el domicilio personal; políticamente es recinto con derechos y obligaciones y privilegios" ${ }^{\prime 2}$. Sin lugar a dudas la casa rural como la urbana pone de manifiesto un estrato social, una cultura y formas de comportamiento al interior de la familia con las costumbres "y prácticas de convivencia y sociabilidad"23.

Una casa campesina en la zona rural del Yacopí, nos la describe Víctor Manuel Murcia Camargo ${ }^{24}$, maestro de obra en la época, quien nos manifiesta que las casas en el campo se construían en bahareque ${ }^{25}$. No hay base en los cimientos de la casa. Sólo el que se realiza a las columnas y los estantillos. Al envigar se determina si el techo es de un agua o dos aguas. La mayoría de las casas se hacían en dos aguas que significan dos caídas de agua en la cubierta. Es decir, se divide la techumbre por la mitad y se enviga con madera para luego colocar la teja de zinc o la palmicha ${ }^{26}$. El piso era de tierra pisada, sólo las casas de los más ricos podrían llevar madera en el piso. Finalmente, se pasaba a la labor del pañete en las paredes y en los cielos rasos en las casas de los más "pudientes". Se pañeta con la mezcla de tierra y cagajón de caballo ${ }^{27}$. Las camas, para dormir, se construían sobre el piso de tierra clavando cuatro estacas de madera y colocando encima unas tablas. Arriba de estas tablas se

\footnotetext{
22 Gonzalbo, "Vida cotidiana", 186.
}

23 Gonzalbo, "Vida cotidiana", 188.

24 Víctor, natural de La Palma que nació en el año 1923. Se caso con Rosa Helena Triana de Bustos, natural de Yacopí, compañera de estudios en el colegio de la Sra. Teresa, de Amparo (1926- ) la maestra de nuestro estudio. Entrevista a Víctor Murcia, en Fusagasugá, 26 de agosto del 2012.

25 El bahareque, sistema constructivo con caña o esterilla de guadua que se entrelazaba y se le daba consistencia y refuerzo con una mezcla de tierra y cagajón (boñiga) de caballo que era como el mortero de cemento y arena actual. Entrevista a Víctor Murcia, el 9 de abril del 2011 y el 12 y 26 de agosto de 2012, con una edad de 83 años y en plena lucidez mental.

26 La palmicha o palma Iraca es una palmera. Las hojas de gran diámetro se dejaban secar y estas colocadas sobre entramados de madera o bahareque constituían la cubierta o techo de las casas.

27 El cagajón de caballo era el que servía. Se ponía a secar. Se colocaba en un hueco se pisaba hasta volverlo harina. Luego se le revolvía tierra amarilla, gredosa, que era la de los hormigueros y de allí salía una mezcla especial para pañetar. Entrevista a Víctor Murcia. Fusagasugá, 26 agosto del 2012. 
instalaba la estera que comúnmente le denominaba el junco ${ }^{28}$. Este junco correspondía al colchón.

Además, de las habitaciones para dormir se construía la cocina, que podía estar cerrada para "que los animales no se entraran". El fogón se hacía en lo alto y se construía con barro. Se colocaban tres piedras y se cocinaba con leña. Encima del fogón se colocaba una cuerda para ahumar la carne. Las casas más pudientes tenían un cuarto para guardar los aperos y el maíz seco. Además, la estufa era de hierro y tenían horno para asar las arepas.

Las casas se construían cerca a una quebrada o chorro de agua. O se trataba de buscar el "ojo de agua" para tener agua para la comida. El lavado de ropa se efectuaba sobre una piedra en la quebrada. Tampoco hay que olvidar que, en general, no existía el baño ni el inodoro. Nos relata Víctor que: "se hacia del cuerpo debajo de los cafetales. Por eso la gallina campesina y los huevos eran de alimento". Se salía al campo a hacer "las necesidades" o se hacían en la "vacenilla" 29 , que se utilizaba en las noches y luego se votaba en las mañanas. Hay que decir, que este objeto sanitario era un elemento que tenían casi todas las familias junto con un platón y una jarra para bañarse la cara y las manos en las mañanas. Estas últimas eran utilizadas principalmente por el padre de la casa.

Se tenía un patio con el "botalón" para amarrar las bestias y el ganado 30 y no podía faltar el solar, que le daba vuelta a la casa, para la huerta casera. Las casas estaban separadas por distancias considerables según el tamaño de las fincas. En general, todas las casas tenían su huerta de "pan coger" con las matas de plátano, yuca, maíz, unas gallinitas para los huevos y el perro guardián de la casa que avisaba, con sus latidos, la llegada del forastero. El agua se traía del arroyo más cercano. Los más pudientes tenían una alberca de cemento. El baño del cuerpo se hacía en el arroyo o con el agua de la alberca a "totumadas".

Por otra parte, la casa del pueblo tenía espacios de sociabilidad. Se disfrutaba de un espacio para la sala y otro para el comedor, diferente al de la cocina donde comían los empleados. Quizá sea la casa del Dr. Arango la que nos muestre en detalle la vida cotidiana, y la sociabilidad de esta familia en el pueblo de Yacopí.

$28 \quad$ Junco es una palmera cuyas hojas secas se recogen y se van organizando en trenza para formar una malla compacta que queda organizada en una esterilla.

29 Entrevista a Murcia, Víctor, Fusagasugá, 26 agosto del 2012.

30 Poste de madera para amarrar el ganado y los caballos. 


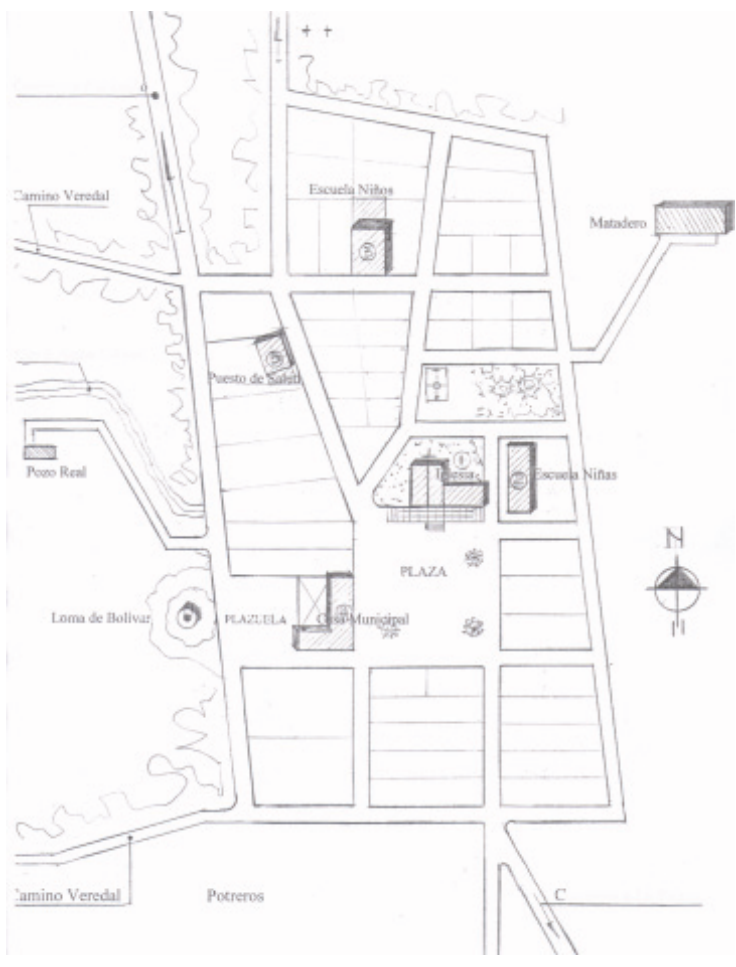

básicos de agua, luz y el alcantarillado, aunque habían construido el de aguas lluvias. Las calles eran en tierra pero los andenes en cemento.

Hay, sin embargo, que mencionar que el pueblo, constaba de una gran plaza central cuadrada ${ }^{33}$ con tres árboles: dos de chupos y uno de pomarroso. En esta plaza se encontraba la iglesia con un amplio atrio por encima del nivel de la plaza, con barandas en balaustres de concreto que ocupaba todo un lateral con la casa cural, construida en ladrillo y cemento, la alcaldía y las casas de las familias principales que en términos de los entrevistados eran los de la "jai". En la plaza principal y en la plazuela se efectuaba el mercado: los días domingos el principal y el día jueves uno secundario. El comercio se centraba principalmente, en la plaza principal. Se tenía dos farmacias: la del Dr. Arango ${ }^{34}$ y al frente la de los Téllez; La tienda de los Chica, el almacén de

\footnotetext{
31 Calculan los entrevistados que no pasarían de 500 habitantes.

32 Tienda donde se conseguía elementos de construcción y miscelánea.

33 Véase plano, anexo, de la ciudad elaborado por el arquitecto Euclides Arango en el año 2011 para este libro. Es un recuerdo del pueblo en su conformación en el año 1948.

34 Enrique Arango Botero (1888-1946). Para el Dr. Enrique Arango su orgullo era el ser paisa como lo señala Euclides Jaramillo Arango" soy eminentemente antioqueño. Como si una gata, como reza en el cuento inglés, pare en un horno lo que pare son gatos y no panes. Paisas los padres, paisas los hijos". Jaramillo Arango, Euclides. Un extraño diccionario. (Medellín: Editorial Bedout, 1980) 10.
} 
los Chacón únicos conservadores del pueblo. El almacén de telas contigua a la casa de los Chacón. La alcaldía era una casa esquinera que en la parte de atrás daba con la plazuela. Allí, se localizaba el telégrafo que funcionaba con "grandes pilas".

En general, la gente del pueblo de Yacopí debía traer el agua del "pozo real" 35 . Los solares de las casas tenían sembrados naranjos, plátanos y café. Los de la "jai" del pueblo, todos tenían finca ${ }^{36}$ en el campo con ganado, cultivos de plátano y café. Estas familias contaban mínimo con tres personas de empleadas del servicio doméstico. La de la cocina, la del aseo y la "nana"37 de los niños. En Yacopí sólo había dos radios: El de Don Pacho Rueda que se prendía todas las noches en su almacén y la gente se iba allí a oír las noticias. El otro, el de Daniel Infante, era de su uso privado.

El primer carro debió llegar hacía 1947. Este carro lo trajo un italiano, el Sr. Tontini, quien cobraba cinco centavos a cada persona que quisiera montarse y dar la vuelta a la plaza. En el mismo año llegaron los buses de la Flota Rionegro y al poco tiempo también los de la Flota La Palma que realizaba el trayecto de Yacopí, La Palma, Pacho, Zipaquirá y Bogotá. Igualmente, hicieron presencia en el pueblo los carros combinados que los llamaban mixtos. Es decir, la mitad para pasajeros y la parte de atrás para la carga. Al pueblo llegaba el periódico El Tiempo todos los días. Este negocio estuvo, en los inicios, bajo la administración de dos hermanos de Amparo. Primero, el corresponsal fue Luis y posteriormente continúo con esta venta Manuel Antonio. Entre semana vendía 30 ejemplares y los domingos se podía llegar a 50. Entre los medios de comunicación se tenía el telégrafo. Allí trabajó Emira, hermana de Amparo, en el año 1948 con un salario de 50 pesos al mes.

Quizá la diferencia más notable, entre los estratos sociales rurales, sea que la casa del "jornalero", carece de un aljibe, alberca, cisterna, cocina en lo alto con estufa de hierro, no tiene piso en madera, ni cielo raso, y por supuesto tampoco habitación para los amarros. En el campo, la mejor vajilla era de material de "peltre" y las cucharas de palo, las ollas de barro para el agua y el guarapo y para cocinar de aluminio. La visita se recibía en el corredor, bajo el alero de las casas, y se sentaban en butacas.

\footnotetext{
Correspondía a un gran tanque municipal ubicado a las afueras del pueblo.

La finca del Dr. Arango se llamaba "Alto seco" y quedaba a siete horas de camino.

La "nana" correspondía a la niñera que para el caso de Amparo se llamaba la "nana" Placer.
} 


\section{De su pueblo al camino de herradura y vereda rural}

Se podría decir que el tipo de construcción que hemos descrito, con las respectivas costumbres del campo, en esta zona de Cundinamarca era similar a la que encontró Amparo al asumir el magisterio en las veredas de clima cálido como fue en la zona de Miraflores con las veredas de Guamal y Suna Abajo. En los climas fríos como Siachoque, Togüí, Arcabuco Rondón, Tunjita cambiaba la construcción y el vestido del campesino. Debemos indicar que en las dos primeras escuelas se encontró con una construcción de un salón, y habitación para la maestra ${ }^{38}$. En la tercera escuela, no se tenía un lugar construido para ejercer la función docente. Por este motivo, realizó las clases en la casa "las Delicias" de la familia Suárez Díaz quienes cedían un espacio de la casa para desarrollar la labor de la enseñanza. De todas maneras se debe tener presente que en esta casa de don Emeterio y doña Carmen, le otorgaron alojamiento. Allí la maestra, convivió con los cuatro hijos de la familia: dos mujeres y dos hombres. Como era costumbre, en aquella época, en la casa se alojaban la señora que ayudaba en la casa, y familia que "nunca faltaba". La casa tenía tres habitaciones seguidas. Precisamente, Amparo compartía habitación con las mujeres. Además, existía la habitación para la enseñanza, que presentaba piso de madera. Y, una habitación para el granero y los "aperos" y la cocina en piso de tierra. Toda la casa construida en adobe y tapia pisada, con alero y techo de teja de barro. El río "Pómeca" pasaba a cien metros y allí se bañaban el cuerpo y se lavaba la ropa sobre una piedra. La "loza" 39 se colocaba en una "artesa" de madera y se lavaba en la cocina. No había alberca. El agua para cocinar se cargaba en "vasijas". Existía una letrina en esta casa, esta era una gran diferencia, como hemos indicado, de una casa de propietarios con medios económicos altos ${ }^{40}$, frente a las casas de la gente del común. Estos hechos que hemos descrito ocurrieron, hacia el año 1955, en la escuela "Alcaparroca", en la vereda de Peñas Blancas, del municipio de Arcabuco. Precisamente, en ese año percibió un salario de 130 pesos, que recibía en botellas de aguardiente en el estanco. No se puede olvidar que Colombia es un país donde la educación se financiaba "gracias" al impuesto sobre la lotería, la cerveza y los licores nacionales ${ }^{41}$.

38 Inicia el desempeño docente como maestra rural el 10 de marzo de 1953, en la categoría de aspirante, con 85 pesos, en la escuela de "Tocavita en el municipio de Siachoque, pueblo conservador. Al año siguiente el 21 de enero inicia actividad docente en la Escuela de "Gachanzuca" en el municipio de Togüí, pueblo conservador, con un salario de 100 pesos.

39 Se le denominaba a la vajilla que casi siempre era de un material denominado peltre.

40 Entrevista a Pacheco, William, Tunja, 24 de agosto del 2012.Ahijado de Doña Carmen, que vivió en esta casa.

41 El Decreto 2838 del 25 de septiembre del año 1938 estableció el 2\% del impuesto a las loterías para financiar la educación. En ese mismo sentido lo ratifica la Ley 1 de 1961. Pero durante el gobierno del General Rojas Pinilla en el año 1955 expidió el Decreto Legislativo 2956, donde en el artículo 8 estableció 1 peso de impuesto a cada botella de licor destilada en Colombia. Esta normativa se continuo legislando en 1963 con el Decreto -Ley 3288; 1966 Decreto Ley 1595; en 1968 con la Ley 33. 
Pero quizá sea en la vereda del Guamal, donde podamos establecer las vivencias de la historia de vida de la maestra Amparo, para poder diferenciar las concepciones urbanas y el adaptacionismo al medio rural por parte de ella. La maestra se posesiona como todos los años en el mes de enero. En este mes les indicaban a las maestras, en la Secretaria de Educación de Boyacá, dónde sería su próximo lugar de trabajo. En esta ocasión en su documento se le indicaba de un traslado y debería tomar posesión en el pueblo de Miraflores. Hay que decir, que ella el año anterior había trabajado en la Escuela Rural de Rodríguez en Jenesano, a una hora del pueblo, y según manifiesta este traslado se debió a la "pura pasión" de un supervisor por no "darle los favores" ${ }^{42}$. El asunto es que ella se encamina al pueblo de Miraflores, según le indican liberal, y que se encontraba a siete u ocho horas de distancia de la ciudad de Tunja, capital del Departamento de Boyacá.

El viaje lo realizó en bus, de Tunja a Miraflores, a través de una carretera destapada, de una sola vía, que presentaba casi siempre deslizamientos de tierra y en épocas de invierno se tornaba intransitable porque los buses no podían atravesar las quebradas. Las horas de viaje podrían oscilar entre 7 y 12 . Allí, en el pueblo de Miraflores, se posesionó del cargo ante el señor alcalde, el 21 enero de 1959. El salario para ese año sería de 200 pesos mensuales. La maestra, como era costumbre se presentaba igualmente, ante el cura párroco que le orientaba en la obligación de asistir a las celebraciones de las fiestas religiosas.

Para ella, una buena noticia era el haber llegado a un pueblo liberal, pero lo que nunca se imaginó era que su "escuelita de la vereda de Guamal" le quedaba a tres días de camino a pie. Sin embargo, con un pensamiento positivo manifiesta que la distancia era "algo bueno porque ningún supervisor le iba a llegar a controlar y a fregarle la vida". En ese entonces como nueva forastera en el pueblo llega a una casa de familia que la acogió con su hija y le dieron la "posada" y la comida. Además, le indicaron la tienda y el almacén donde se podría hacer cliente y luego gozaría de la preeminencia de persona a la que se le podría "fiar" el mercado. En Miraflores al maestro, en general, se le fiaba en las tiendas y almacenes del pueblo. Quizá, fuera obvio está situación porque estos empleados del gobierno tenían un sueldo fijo que, aunque se demoraba, siempre llegaba.

42 Se posesiona con la Resolución 002 del 19 de enero de 1959 con un salario 200 pesos. Labor con niñas. Restaurante escolar. Internado para niños de lejos. Se lleva al sobrino Luis Alberto. En ese año era Presidente Alberto Lleras Camargo; Gobernador en Boyacá, Luis M. González; Secretaria de Educación María Martínez Guanín. En esta vereda está del 21 enero 1959 a 25 diciembre del año 1960; el 21 de enero del año 1960 se posesiona por segundo año en la Escuela Guamal con un salario 300 pesos 
Como hemos indicado la escuela quedaba a tres días de camino. A estos caminos se les denominaba de "herradura" que consistía en trochas que con las lluvias se tornaban intransitables. Inició su viaje con los elementos básicos que podía llevar cargados en un "talego"43 de tela. A su hija sólo le daba una bolsa pequeña con unas frunas y colombinas ${ }^{44}$ para el camino. Manifiesta, que no le daba a su hija más encargo de llevar, dado que "era suficiente con que se defendiera de no quedar enterrada en el barrizal". Los elementos básicos que llevaba eran: "una muda de ropa, una sabana, un cuaderno, lápiz, pan de trigo para regalar y el "comiso"45 para el camino".

Esta primera jornada la recuerda la maestra como algo traumático. Comenta que un señor que pasaba a caballo le regalo cinco pesos al verla en medio del barrizal con su hija. Sin embargo, el camino lo hizo placentero para su hija enseñándole a coger la "caña brava", cuyo tallo se masticaba y salía un líquido agri-dulce que se consumía en lugar de agua. Además, "eran abundantes las guayabas y unas flores que también calmaban la sed". Al anochecer llegaron a la casa de los Rodríguez. Iba recomendada por una familia de Miraflores y les dieron la dormida y aguepanela con arepa para la cena. Claro, la maestra llevó de regalo pan de trigo que era muy bien recibido. La noche la pasaron sobre la estera y en una cama, tal como se ha descrito, de cuatro estacas clavadas en el piso.

Con el canto del gallo, a las cuatro de la mañana, se inició camino para que el sol no les cogiera el paso de la montaña. Según decían, se debía transitar al filo de un pequeño camino que además de peligroso se tenía la noticia de atracos a los viajeros. Además, se decía que allí habían unas cuevas donde se habían escondido los godos para matar a los liberales. Por este motivo era una suerte encontrar a otros viajeros y poder establecer caravana. Salieron muy temprano con una "esperma" 46 encendida y una caja de fósforos. Pero se dieron cuenta que la esperma no servía porque el viento la apagaba. Así que, sin linterna, como un medio de alegrar el camino se recurrió a coger cocuyos abundantes en la zona. En efecto, con estos pequeños animalitos, quizá imaginaban que se alumbraría el camino que también era acompañado por las luciérnagas ${ }^{47}$ que trataban de contar antes que la fugaz luz desapareciera.

43 El talego es una bolsa de tela, quizá guardando las proporciones sería los morrales actuales.

44 La colombina es un dulce redondo que tiene un palo pequeño para cogerlo. La fruna es un dulce que vienen en un empaque de cuatro. Tienen una dimensión de $2 \mathrm{X} 2$ centímetros.

45 El "comiso" denominación que le dan a la comida que llevan para el camino. Algunas veces se le denomina fiambre pero sólo para la comida que va envuelta en hojas de plátano.

46 En Colombia se le denomina esperma a las velas. Estas se elaboraban con cebo de marrano y la mecha de un hilo de algodón. Otras velas más costosas eran las de parafina. Entrevistas a Murcia, Víctor y Arango, Amparo, Fusagasugá, 26 de agosto del 2012.

47 La diferencia con el cocuyo es que éste es de un tamaño como la cucaracha y terrestre y en la parte de atrás tiene permanentemente encendida una luz. La luciérnaga es un insecto volador que enciende intermitentemente la luz de la parte de atrás. 
La maestra pudo comprobar que los comentarios sobre la dificultad de este camino eran realidad. Pero se olvidaba que la caravana no se puede hacer cuando se lleva niños pequeños porque ellos no pueden seguir el ritmo de los adultos. Entre la pequeña apuesta que hacía con su hija, de llegar a un árbol y luego descansar se avanzó de esta manera en el camino y al anochecer se llegó al caserío de Páez. Al arribar a esta pequeña población, sin conocer a nadie, se dirigieron a la casa cural, donde el párroco les recomendó una casa de familia para pasar la noche. Al día siguiente, luego de un baño en alberca y el desayuno, la maestra se dirigió a la casa cural a recibir las orientaciones de las fechas obligatorias, cuando debía venir con los niños al pueblo, para celebrar las fiestas religiosas y patrias.

Por otra parte, no se puede olvidar el mecanismo que se utilizaba para llevar los elementos básicos a la escuela. En el pueblo existían los "arrieros" a quienes se les pagaba y llevaban en burros el trasteo. La maestra Amparo había contratado el arriero en Miraflores. Este señor le llevaría sus objetos a más tardar en un mes, cuando lograra otros clientes para llevar mercado o utensilios a Páez. En Páez ella dejó contratar otro arriero, que hacía el viaje a la vereda de Guamal. Su equipaje de trasteo consistía en "ropa, una cobija, ollas y cubiertos de aluminio, loza de peltre y sus libros de enseñanza"48. Por lo tanto, hasta que le llegarán sus objetos personales todo tendría que conseguirlo de prestado.

La última etapa de Páez a la vereda de Guamal era de otro día de camino. La vereda de Guamal, se iniciaba pasando el río Upía y llegaba hasta el pico de la montaña. La escuela quizá quedaba a mitad de camino entre estos dos linderos. Puede decirse que para llegar a la escuela, lo más peligroso se centraba en el paso del río Upía que se realizaba en canasta, porque no había puente, Pero lo esencial era llevar un palo que servía de apoyo en el paso a pie de las quebradas y para defenderse de las culebras del camino.

Esta travesía la realizó Amparo presentándose a la gente como la nueva maestra de Guamal. Antes de llegar a la escuela arribó a una casa vecina donde pidió prestada la estera, una olla, una olleta, cubiertos y un machete. Pero la más importante novedad, en este recorrido, es la primera impresión que ella tuvo de los padres de familia. Este es un recuerdo de gran afecto y agradecimiento hacia aquella familia de los vecinos de su escuela. Manifiesta que, esta familia la acompañó a la escuela y ya se la tenían bien limpia porque las "voces en el campo son más rápidas que la liebre". La maestra había llegado y decían que era una bendición de mi Dios que se la hubiese mandado liberal. Cabe

48 Entrevista a Arango, Amparo, Fusagasugá, 6 de enero del año 2009. 
anotar que a la maestra la vereda de Guamal le recordaba a su región natal. Un clima cálido, abundante en pasto, siembras de yuca, plátano, maíz y caña en algunas fincas. Sus pobladores, todos colonos que "a punta de machete" habían talado los bosques habían construido sus casas y pequeñas huertas de "pan coger" y algunos habían logrado más hectáreas que destinaban para el pasto del ganado. Comenta, que un buen número de campesinos no tenían aún documentos de propiedad de las tierras. $\mathrm{Al}$ día siguiente, el recibimiento fue "por lo alto" 49 . Comenta que "desde bien temprano llegaron en especial las madres de familia, todas con canastos que contenían amasijos, yuca, plátano, mazorcas, maíz, ñame, carne, papas, panela, una botella de leche y hasta dos gallinas ponedoras ${ }^{\prime 50}$. Comida no faltaba pero lo básico de su modo vivir de niña de la "jai" no existía.

Cómo hemos indicado, se había posesionado del cargo el 21 de enero de ese año 1959, y allí estaba en su escuela a finales del mes, lista para iniciar actividades a comienzos de febrero. Consideramos que quizá a ella le ayudó el adaptarse, a este medio rural, el hecho de proceder de un pueblo liberal y que este trabajo era la única solución económica a su desplazamiento y desde esta perspectiva era el medio de supervivencia para ella y su pequeña hija. Pensamos sin embargo, que su capacidad de adaptación lo resume en su frase "al mal tiempo buena cara". Por otra parte, la escuela tenía casa y por lo tanto, por el momento no tendría "que mendigar la posada". La escuela estaba construida en adobe con tejas de zinc. Un cuarto grande, con ventanas, que se destinaba al salón de clase. A continuación se localizaba la habitación de la maestra con cama de cuatro estacas. Todo el piso en tierra. Diagonal, una choza que servía de cocina. No existía sanitario, este se construyó en el primer año de su labor docente. Cerca estaba el chorro para el agua y el baño y además una quebrada.

En esta vereda de Guamal se localizaban similares construcciones en bahareque, con techos de palmicha y/o zinc y el piso de tierra. Las camas, se hacían de manera, similar a las descritas en el campo de Yacopí... Es decir, con estacas sobre el suelo de tierra y cubiertas con tablas sobre las que se colocaba la estera de junco. Precisamente, así era la cama de la maestra Amparo en esta vereda. Igualmente, era común este sistema en el pueblo de Miraflores donde, posteriormente, alquilaba una habitación, en la casa de la señora Rosita, cuando venía a esta población cada seis meses a cobrar su salario. Sin lugar a dudas extrañaba las camas de su casa en Yacopí, donde según ella y sus hermanos, existía el mejor carpintero de la región y recuerdan al señor Márquez quien les fabricó todos los muebles de la casa.

49 Significa que la atendieron muy bien.

50 Entrevista a Arango, Amparo, Bogotá, 6 de enero del año 2009. 


\section{Hambre no, pero si escasez de dinero para el mercado de tienda}

La alimentación es uno de los factores que determina los estratos sociales en el campo y la ciudad. Podríamos decir, que existen unos alimentos básicos pero el complemento de la leche y las carnes establece la diferencia. En el pueblo de Yacopí, como en las veredas donde trabajó Amparo en Boyacá, hambre no se presentaba. Desnutrición, quizá en las familias de los jornaleros. Mortalidad por desnutrición tampoco. Sin embargo, lo común que se presentaba eran las enfermedades endémicas, los virus y parásitos que atacaban en especial a los niños y por supuesto la mayor mortalidad infantil. Como es de suponer, no existían jornadas de vacunación para los niños en los campos, mientras que en los pueblos llegaban en ocasiones, la vacuna de la viruela y la del sarampión. Precisamente, una actividad de la maestra era lograr la vacunación de sus niños, llevándolos al pueblo al puesto de salud. Sin embargo, se desplazaban sólo unos pocos niños, debido a las distancias. Por supuesto, no recuerda que hubiese ido en estos dos años alguna jornada de vacunación, a su vereda de Guamal.

La alimentación de Amparo en Yacopí era: caldo de papa con carne o con huevo; un tazón de leche con "pan de dos" 51 y plátano asado. Algunos días, comentan en las entrevistas sus hermanos que, les daban chocolate o café con leche. Tenían las medias nueves que consistían en agua panela con leche, pan y una fruta. El almuerzo, casi siempre sancocho con carne, arroz y plátano y el agua panela con leche. Las onces, se repetía lo de las medias nueves. La cena se repetía lo del almuerzo y para acostarse se tomaban una taza de chocolate con pan. Su padre decía que el chocolate era de alimento y ayudaba a la inteligencia ${ }^{52}$.

En la zona rural de Guamal, las familias de menores recursos económicos los de los jornaleros, usaban los productos de la tierra para el sustento diario. Por el contrario, las gallinas y los huevos debían guardarse para la venta o para establecer el trueque con el mercado de tienda del pueblo. En general, la dieta alimenticia era simple y repetitiva. La alimentación en el campo, iniciando por el desayuno, a los niños no les podía faltar el agua panela sola o con leche o el agua café ${ }^{3}$ con el plátano asado o arepa de maíz. De ahí en adelante se establecía la diferencia: el caldo de papa, al cual se le agregaba carne o huevo cuando se tenía. El almuerzo, un sancocho. Este es una especie de sopa

\footnotetext{
Se le daba este nombre porque tenía un valor de dos centavos.

Aún hoy una nieta del Dr. Arango que es pediatra recomienda tomar el chocolate antes de acostarse.

3 El agua café consistía en café mezclado en agua panela. Es decir, se le incluía el café se ponía a cocinar. Luego se dejaba esclarar para que el café se fuese al fondo de la olleta. Luego se servía.
} 
que incluye en una olla con agua, los siguientes elementos: yuca, arracacha, ñame, plátano verde, papa y mazorca. Quienes tenían le adicionaban carne o un huevo con cáscara. Sólo en ocasiones especiales se hacía el sancocho de gallina. Hay que decir, que el maíz en Boyacá es un alimento que se prepara de diferentes maneras. Cuando está blando se utiliza la mazorca asada y en el sancocho. Cuando está seco se "tuesta," se muele y se saca una harina que se utiliza en sopas de sal y de dulce. La papa es más utilizada en la zona cerca de la capital, la ciudad de Tunja. Los hombres, para la jornada del trabajo diario, llevaban el guarapo ${ }^{54}$ en un recipiente de totumo ${ }^{55}$. El almuerzo, lo cargaban en el fiambre ${ }^{56} \mathrm{y}$ por la noche regresaban a la cena que variaba desde sancocho hasta agua panela con plátano. Se podría decir, que el "huevito" lo consumían los niños con su plátano asado y el agua panela con leche en el medio rural. No recuerdan los entrevistados de Yacopí y de Miraflores que se presentará situaciones de hambre en el campo. En la huerta de "pan coger" siempre se encontraba algo para "echar a la olla". Sin embargo, la maestra comenta, que en varias de sus veredas, donde ella trabajó, los huevos se recogían para sacarlos el domingo a la "plaza de mercado" o los vendían en las tiendas del pueblo, donde realizaban el trueque por el "mercado de tienda". Y, con frecuencia, el trueque se realizaba en la misma vereda.

Precisamente, por esta situación la maestra consideraba que no estaban "bien nutridos sus niños" y ante la distancia de las casas a la escuela, algunas ubicadas a tres horas de camino, ella inició en el año 1959 el restaurante escolar en la vereda de Guamal. Allí organizaba una gran olla donde se incluía todo lo que traían los niños. Los que llevaban carne, se les daba su pedazo, pero dice que la "sustancia quedaba en el sancocho y le servía a todos los niños". Igualmente, inició la huerta escolar con la siembra de yuca y de maíz en el lote que tenía la escuela. De esta huerta se surtía el restaurante escolar. Además, tenía gallinas y los huevos eran para su consumo y para el de los niños que no traían ni siquiera un "huevito". Comenta que a la entrada de la cocina tenía colgado un canasto y éste era el "canasto de su papá," porque siempre estaba lleno de amasijo. Es relevante que el plátano era un alimento básico. El plátano verde se cortaba en rodajas y se ponía a secar al sol. Luego se molía y con esta harina se preparaba la sopa de sal o de dulce. A esta última se le agregaba leche.

Bebida que se realizaba con el jugo de la caña. Se ponía a fermentar en ollas de barro.

55 El totumo, es un árbol que produce un fruto grande como un balón, con cáscara fuerte. Una vez tenga el fruto un color rojizo se considera que está "Jecho" es decir listo para coger. Se le hace un orificio, se le saca las semillas y se pone a secar. Cuando s e partía por la mitad, quedaban dos recipientes tipo taza para servir el agua o el guarapo. Se le llamaba la totuma. El Calabazo es de la misma familia de los totumos, la fruta es alargada. Igualmente, se le sacaba la semilla a través de un orificio que se le hacía en parte más delgada. Este ese utilizaba para cargar el guarapo.

56 El fiambre consistía en colocar en hojas de plátano, pasado por el fuego, la comida de: arroz, plátano, yuca, papa y un pedazo de carne. 
La situación crítica que vivían las familias más pobres del campo, era el no tener dinero para comprar los alimentos básicos en la tienda del pueblo: arroz, sal, azúcar, panela, espermas y los fósforos ${ }^{57}$. Hay que decir que, en esta época la manteca del cerdo se utilizaba para las comidas y para hacer una especie de alumbrado con una mecha que ya hemos descrito anteriormente. Recuerda que en la casa del señor Morales tenían una lámpara de petróleo y un radio de pilas. Por otra parte, los artículos, como las telas para el vestido ${ }^{58}$, el calzado, las cotizas o los zapatos para los niños se compraban cuando se lograba la venta de una res o del ahorro de los huevos y de la leche que se vendía.

Debemos conocer que hacia el año 1950, el salario de un jornalero, ayudante en la construcción, era de 4 pesos semanales en Yacopí y La Palma y se le incluía la comida. Es decir, 16 pesos al mes. Nos comenta Víctor que él hacía el mercado para la finca de su papá. Cargaba una mula con dos bultos y todo le costaba 5 pesos $^{59}$. La diferencia de salario era alta en relación al que se recibía en la capital del país en Bogotá. En el caso de Víctor, desplazado en el año 1953 a Bogotá, trabajó en lo único que sabía hacer: la construcción. Allí, en la capital recibía un salario de 20 pesos a la semana. Es decir, 80 pesos al mes casi igual a lo que percibió la maestra Amparo en su primer año de trabajo en $1953^{60}$. Podríamos añadir que el maestro de obra Víctor Murcia, pagaba en Bogotá una habitación de 30 pesos mensuales y el resto para la comida y los gastos de su familia. En esa época el señor Murcia sostenía a su esposa y dos hijos. Él fue uno de los tantos pobladores que no se adaptó en la capital y tan pronto tuvo la oportunidad de regresar al pueblo, lo hizo, sin embargo, luego nuevamente emigraría a otra población en el año de $1960^{61}$.

\section{La transición del "pie limpio", a la cotiza, al zapato croydon y la bota de caucho}

El vestido del campesino en la vereda de Guamal consistía en un pantalón de dril y una camisa de "tierra caliente," pero se acompañaba de la ruana para las tardes o para el viaje a la montaña. Además, era imprescindible el sombrero de fieltro para el sol. Pero en las escuelas de tierra fría, como Tunjita o Rondón,

\footnotetext{
Cuando se acababa la que se producía en las moliendas de la vereda.

La ropa siempre se mandaba hacer.

59 Nueve años después en el camino de Miraflores a Guamal un señor les regala cinco pesos. El salario de Amparo en ese año era de 200 pesos.

60 La maestra Amparo, en ese su primer año de trabajo de maestra rural en Boyacá, en la categoría de aspirante ganaba 85 pesos en el año 1953. Archivo DSA, Fondo Maestras.

${ }^{61}$ En el año 1960, se trasladó a la población de Fusagasugá, incialmente en alquiler de vivienda luego compró un lote que construiría para después vender y de esta manera inició un prospero negocio de compra y venta de lotes y casas, que le dan la rentabilidad con la que vive actualmente en su vejez.
} 
entre otras, en las que trabajó Amparo, se utilizaba la ruana de lana y un sombrero. Lo común era andar a "pie limpio". En esa época, dentro del pueblo se usaban unas buenas cotizas y sombrero de paja, que se llamaba "jipa", el más económico en Boyacá era el "pastuso"62. Quizá, en el sombrero y en el calzado se diera la distinción de lo urbano y lo rural. El señor del pueblo con zapatos y sombrero de un material de paño que se llamaba fieltro y el más "fino" era el "borsalino". Amparo, en su magisterio vivió la evolución del vestido y del calzado. Ella comenta: "el campesino caminaba a pie limpio sin embargo cuando llegaban al pueblo se colocaban las cotizas ${ }^{63}$ tanto los hombres como las mujeres, pero estas últimas preferían las alpargatas ${ }^{64}$.

Pero, quizá en este departamento, la vestimenta en el medio rural tenía características diferentes. La mujer utilizaba falda y blusa y las niñas el vestido enterizo. Para montar a caballo, utilizaba los zamarros y debajo un pantalón". Pero lo que si evolucionó fue la falda. Estas a medida que fueron pasando los años se fueron recortando de media pierna más cerna al tobillo hasta llegar a la rodilla. Las blusas eran de colores pero la más elegante: las blancas. La maestra usaba vestido enterizo, Faldas y blusas de colores. Pero, en los años 1970 ya utilizaba el pantalón como vestido diario.

Los niños de la escuela de Guamal y de Tunjita, llegaban a "pie limpio". Se lavaban los pies en el chorro y se ponían sus cotizas (niños y niñas) o alpargatas (niñas). No existía uniforme. Los niños de pantalón corto o largo, su ruana y sombrero. Las niñas de vestido que llegará a media pierna, de la rodilla hacia abajo, una ruana y su sombrero que cubría la larga cabellera que se peinaba en dos trenzas. Sin embargo, para las festividades en el pueblo se debía llevar un uniforme. Asistían los niños que pudiesen conseguir el uniforme y eran afortunados los que lo habían heredado del hermano o hermana mayor. En los niños: pantalón negro y camisa blanca, con zapatos o cotizas. Las niñas con "jardinera" ${ }^{65}$ negra y blusa blanca. Con zapatos negros y medias blancas. Los zapatos eran iguales para niños y niñas. Se compraban a partir de los años sesenta, los de croydon porque duraban más. Por ejemplo, la maestra le adquiría a su hija los "zapatos de amarrar croydon". Se conseguían grandes para que duraran. Quizá, lo que más evolucionó fue el calzado en los años setenta, cuando se dio el inició en esta región al uso de las botas de caucho o "pantaneras".

\footnotetext{
62 Nombres y clasificación de sombreros dado por entrevista Ayala Poveda, Hernando, 24 de agosto del 2012. Sus padres tuvieron negocio de sombreros y vendían en varios sitios de Boyacá.

63 La cotiza tenía la suela de un caucho fuerte y encima una tela.

64 La alpargata, se hacía de cabuya la suela y la parte de arriba de tela de algodón.

65 Falda con prenses y con espaldar cubierto y en la parte delantera tirantas.
} 
También debe destacarse el hecho que los jóvenes que fueron al ejército, al regreso se encontraban que ya no pertenecían a ese sitio. Por lo tanto, un buen número se quedaban en la ciudad, a buscar otras oportunidades de trabajo.

\section{La familia patriarcal, los compadres, y los hijos naturales en el campo y en el pueblo.}

La estructura de la familia estaba conformada bajo la rígida autoridad paterna y fuerte cohesión religiosa. Desde esta perspectiva, socialmente estaba organizada por la pareja "unida en santo matrimonio católico, indisoluble hasta la muerte", que producía efectos civiles. El divorcio en Colombia sólo se logra a partir de la constitución de 1991. Esta situación del matrimonio indisoluble católico ya había sido cuestionada y se estableció por la Ley del 20 de junio de 1853, en el artículo 30, que "el matrimonio podía ser disuelto bien por muerte natural de uno de los esposos o bien por el divorcio". Sin embargo, la posibilidad del divorcio sólo duraría tres años, porque fue derogado por la Ley del 8 de abril de 1856 y su prohibición fue reiterada en la Ley del 15 de abril de 1887.

Debemos recordar que el matrimonio católico era monógamo. En la práctica se aplicaba esta monogamia a la mujer y no al hombre. El hombre tenía su esposa y casa oficial de su familia. Este hecho no impedía que se dejara descendencia en otras mujeres de la región. La familia de Enrique Arango, padre de Amparo, estaba conformada en el primer matrimonio por seis hijos: Cuatro hombres y dos mujeres. Más una niña que se "recogió" y se integró a la familia. No olvidar que estas familias tenían varias empleadas que vivían en la casa: Placer y Concha de niñeras; Eusebia en la cocina; además la del aseo; la del lavado y planchado de ropa y el chico de los mandados. Todos ellos vivían en la primera planta de la casa y comían en el comedor de la cocina. Del segundo matrimonio se fueron agregando seis hijos, pero a su vez se fueron independizando los mayores y la hija Oliva quien se casa a temprana edad. La maestra de nuestro estudio queda con cuatro meses a la muerte de su madre y entre la niñera Placer y su abuela Popa sale adelante. Si bien ella compartía la casa contigua a la paterna, con su abuela, nunca dejó de comer en la casa de su padre, dado que él repetía "la familia que come y reza unida permanece unida". Esta situación se aplicaba para las horas del desayuno, el almuerzo y la cena donde era obligatorio estar en la mesa grande del comedor, presidida por su padre el doctor Arango. Aún más, "se cerraban las puertas y no era permitido la interrupción por parte de extraños en las horas de comida" ${ }^{\circ 6}$.

66 Entrevista a Arango, Mariela, 17 diciembre del 2009. 
Como lo hemos señalado antes, la familia de Amparo, giraba en torno a la figura paterna con una fuerte autoridad patriarcal ${ }^{67}$, a quien se le respetaba, obedecía y veneraba. Para todos sus hijos, él era una persona que físicamente se caracterizaba por ser "alto de ojos azules como el cielo". Las hermanas de Arango le llamaban el "Chamizo". Para él, la mujer sólo debía recibir la educación necesaria que garantizara el ser una buena esposa. Era suficiente educación con la que se impartía en el pueblo. Luego, deberían aprender a coser y cocinar como única manera para saber organizar su nuevo hogar. Pero en el caso de Amparo que era su hija protegida, por haber quedado huérfana a tan temprana edad, a ella le permitía acompañarlo a los partos y a pequeñas cirugías que realizaba en el consultorio de su casa de Yacopí ${ }^{68}$.

El asunto es que, desde esta perspectiva patriarcal, no admitió que sus hijas salieran a Bogotá o a Pereira a estudiar. Comenta, Emira ${ }^{69}$ que a Bogotá se les permitía ir sólo de paseo, pero nunca a estudiar, porque según su padre allí "sólo aprendía a pintorretearse las mujeres". Por lo tanto, a está familia de Yacopí, el padre le negó la oportunidad de continuar estudios en la Palma o en Bogotá, como sí lo hicieron sus amigas las Sánchez y las Álvarez. "El Colegio a donde se desplazaban las niñas que salieron a estudiar a Bogotá era el de "Los Ángeles," que tenía internado y enseñaba comercio". Por el contrario, las del caserío de Ibama se desplazaban al Colegio de María Auxiliadora de Soacha, donde había estudiado la maestra Andrea Linares. Debemos indicar que a partir de la muerte del doctor Arango, su hija Mariela, fue la primera que emigró a Bogotá para realizar los estudios de comercio. Luego lo harían sus hermanos Manuel y Euclides a La Palma y posteriormente a Bogotá, donde ya se escolarizó el resto de los hermanos menores. Comentan los hermanos de Amparo que esta idea del estudio era de su madre, Elvira Linares.

La mentalidad patriarcal era el común denominador en el pueblo y en las veredas donde ejerció Amparo su actividad docente, en las Escuelas rurales. Es así, que el diálogo, respecto a la necesidad que estudiaran las niñas, ella lo establecía con el "jefe de la familia," recordando quizá que quien tomaba las decisiones era el hombre como lo había realizado su padre y luego su esposo. Desde esta perspectiva, es relevante señalar la labor que desarrolló Amparo con los padres más pudientes en la vereda de Guamal.

\footnotetext{
67 Susy Bermúdez, "Hijas, esposas y amantes" (Bogotá: Ediciones Uniandes, 1994), 23. El término patriarcado "ha sido utilizado de diversas formas en los escritos relacionados con la subordinación de la mujer".

68 Entrevista a Arango, Amparo, Bogotá , 6 de enero del 2009.

69 Emira, hermana de Amparo actualmente con 84 años y con una mente muy lúcida.
} 
Ahora bien, podríamos añadir que las relaciones sociales para afianzar la amistad entre familias tanto en el campo como en la ciudad, se constituía a través del compadrazgo. Cuando nacía un nuevo niño los padres pensaban quien sería su padrino. La persona seleccionada para esta función debía ser a quien se le tuviese afecto y respeto. No hay duda que era un honor que se le hacía a la persona escogida. Se le encomendaba a uno de sus hijos. La maestra Amparo, en el trascurso de su desempeño magisterial fue madrina de un sin número de niños y niñas. A quienes se les debía dar el vestido para el bautizo. Luego, estar pendiente de ellos. En efecto, más que esto era la relación afectiva y social que se establecía con cada una de las familias del niño o niña.

El hecho es de sobra conocido, que para esta época, en una vereda la mayoría de los habitantes mantenían algún tipo de relación en compadrazgo. Pero hay que decir, que esta relación no fue lo suficientemente fuerte para mantener los lazos de amistad cuando llegó el período de la violencia política. Allí, lo prioritario era el partido liberal o el conservador según el caso. No se olvida que quien no perteneciera al mismo partido de inmediato se convertía en enemigo de la familia.

Debemos indicar un hecho en el cual confluyen igualmente lo urbano y lo rural: Los hijos naturales o ilegítimos. Esta categoría se encargaba el cura párroco de indicarlo en la partida de bautizo. La persona legítima tenía todos los derechos civiles que le podía dar su padre y en especial el derecho fundamental a ser reconocido como hijo y ser heredero de sus bienes materiales. Por el contrario, el hijo ilegítimo era una vergüenza para una familia de "bien," como fue el caso que hemos analizado en el estudio de la maestra Andrea ${ }^{70}$. Ahora, sólo nos limitaremos a la historia de la familia de los Arango de Yacopí. Hay que decir, como lo hemos descrito antes doctor Arango tuvo una familia numerosa con sus dos esposas. Con la primera, que murió de 30 años, tuvo siete hijos pero uno murió a temprana edad. Con la segunda, la familia fue de ocho hijos pero dos murieron al nacer. De esta manera, los hijos legítimos en total fueron 12. Comentan los entrevistados que este doctor Arango, "por lo buen parecido tuvo un buen número de hijos naturales". Por supuesto su familia legítima, asi reconocida ante la sociedad porque los contrayentes o esposos se habían casado por el rito de la Iglesia Católica, no reconocía a "los niños bastardos". Sin embargo, en esta familia se estableció relación con los hijos de la señora Useche, que tenía una

70 Diana Soto Arango, "Historias de vida de dos maestras de escuela de mediados del siglo XX en Colombia. Amparo y Andrea. Liberal y conservadora en contextos de la ruralidad educativa cundiboyacense", en 'Educadores latinoamericanos y del Caribe de la colonia al siglo XIX', Tomo III, eds, Diana Soto et al., (Tunja, impresión Búhos Editores, 2011), 335-368. 
panadería a la entrada del pueblo. Con ella el doctor Arango tuvo tres hijos: Marco, quien llegó a ser inspector de higiene; Tulia y Blanca. Tulia se casó en Bogotá y tuvo una hija que se llamó Dila, la que se relacionó con sus tías Arango en Bogotá. Dila, fue dueña de una fábrica y años después le daría trabajo a una hija de Emira.

Esta situación, de los hijos ilegítimos, comentan los entrevistados que "las esposas se lo aguantaban". El padre era quien mandaba. Desde esta perspectiva, no era extraño para la maestra el hecho de los hijos naturales. Es más, ella acogió desde los dos años a un niño, hijo de la empleada doméstica de un abogado en Miraflores y lo crió hasta que el niño completa el cuarto de primaria. Igualmente, por las escuelas donde trabajó Amparo, pasaron, en categoría de internos, varios niños porque vivían muy lejos de la escuela o porque sus padrastros no los querían tener en casa.

Es importante destacar que es hasta el año 1982, con la Ley 29, cuando se establece la igualdad de derechos herenciales entre los hijos legítimos y extramatrimoniales y adoptados. Pero como puede verse esta desigualdad sólo se elimina en 1994 con la Sentencia C 105 de la Corte Constitucional que declara inexequible la expresión "ilegitimo". De esta manera, estos hijos ocultos obtienen todos sus derechos y obligaciones en el Código Civil colombiano, artículo 250.

\section{Del colegio a la escuela rural y los cursos de capacitación}

La maestra Amparo tenía como experiencia educativa sólo aquella que había recibido en calidad de niña de la "jai "en Yacopí. A los ocho años fue al colegio privado de la Sra. Teresa donde realizó los cuatro cursos reglamentarios de la Escuela Primaria. El método era el de la memoria y la enseñanza se centraba en las: matemáticas, religión, sociales, lectura, escritura y ortografía. Precisamente, allí aprendió las reglas de ortografía que aún ahora a sus 85 años repite con gran lucidez. En el primer año llevaban pizarra y el guiz. A partir del segundo año ya tenían cuadernos que elaboraban en la casa con el papel que traía su padre de Bogotá. Aprender la letra cursiva era muy importante. Esta escritura se practicaba con pluma metálica y tinta. El castigo corporal incluía la férula, que era una regla de madera o una rama de rosa seca y con espinas, en la cual se golpeaba la palma de la mano del estudiante, que merecía ser disciplinado. Este se colocaba de pie y frente a sus compañeros de curso. Se estudiaba todo el día desde las ocho de la mañana hasta las cinco de la tarde. En los descansos se iba a la casa a tomar las onces, al igual que a la hora del almuerzo. El colegio era mixto en el primer grado. Todas las egresadas de primaria, que continuaron estudios en Bogotá, ingresaban a primero bachillerato. En general consideran que la educación era muy buena. 
Podríamos decir que el Colegio de la Sra. Teresa era para estudiantes de la clase media alta del pueblo de Yacopí. No utilizaban uniforme aunque las Arango llevaban siempre el mismo modelo las tres hermanas: Amparo, Emira y Mariela. Además usaban medias y zapatos. Los demás niños iban a la Escuela Pública. El colegio estaba ubicado en una gran casa cercana al parque central. Allí se habían acondicionado dos habitaciones con pupitres y todas con un tablero al frente. Hemos indicado que los espacios físicos, la forma de enseñanza y cotidianidad en las escuelas que le correspondió a la maestra Amparo fueron bien diferentes en el medio rural de Boyacá.

De esta manera la experiencia educativa de Amparo se limitaba al colegio privado de la Sra. Teresa. Es evidente que la continuación de sus estudios se dio cuando se vincula al magisterio en Boyacá. Precisamente, es a partir del año 1960 cuando ella inicia su proceso de capacitación. La localizamos, en este año, recibiendo un curso de castellano y metodología, con 40 horas y de aritmética y metodología, con 40 horas. Este curso lo recibió en Bogotá, en las vacaciones de diciembre ${ }^{71}$. Ella continúo con los cursos de vacaciones hasta que obtuvo el título de maestra rural. La maestra Amparo, sólo hasta el año 1965, fue inscrita en la $3^{\circ}$ categoría, dentro del Escalafón de enseñanza primaria $^{72}$. Resulta paradójico que quien le comunica la citada inscripción fue el sindicato de maestros de Boyacá.

Debemos indicar que el entorno histórico de la escuela, como institución pública, es una de las formas de la presencia del Estado en la zona rural. Es a través de esta institución que se trasmiten vinculan los valores culturales. Especialmente, en nuestra época de estudio la función de la escuela radicaba en impartir los conocimientos básicos de la lectura, escritura y matemáticas. Y, fundamentalmente, la enseñanza de la religión católica a través del conocido catecismo del padre Astete y la Historia Sagrada. No menos importante era el establecer la conciencia del espíritu patrio a través de las izadas de bandera. Quizá, lo más relevante sea los ritos diarios, de la oración antes de iniciar clase y cantar el himno nacional. De esta manera se conjugaba lo religioso con lo patrio.

Destacamos por su entidad que la escuela rural era el único mecanismo de presencia del Estado en las regiones donde laboró Amparo, especialmente en las veredas de Guamal y de Tunjita. Por todo ello, podríamos afirmar que era el único medio de transformación cultural que llegaba desde lo urbano a la ruralidad, teniendo en cuenta que para esta época y para estas veredas la radio era un objeto de lujo. Las escuelas eran construidas igual que las casas que hemos detallado en

\footnotetext{
Archivo DSA- Fondo Maestras. Legajo Certificados de estudios. Maestra Amparo Arango.

72 Resolución N ${ }^{\circ} 80$ del 7 de mayo de 1965. Archivo DSA- Fondo Maestras. Legajo Certificados de estudios. Maestra Amparo Arango.
} 
bareque. Algunas en adobe y el techo en tejas de zinc. Los pisos en tierra. La escuela constaba de un salón grande donde había dos ventanas, de madera, por cada costado. Dentro del gran salón se ubicaban las bancas y al frente la mesa con el taburete de la maestra. En la pared un gran tablero donde la maestra escribía las tareas y realizaba las explicaciones. La tiza y el borrador del tablero no podía faltar en el equipaje de la maestra, junto con su material didáctico que consistía en semillas de colores y los libros básicos: El catecismo del padre Astete, y la aritmética de Baldor; la urbanidad de Carreño, la Historia Sagrada, un libro de Historia Patria, el libro de cuentos de Pombo ${ }^{73}$. Todo esto se guardaba en una caja de cartón. El gran salón de clases tenía capacidad para unos sesenta niños y niñas. Los estudiantes se ubicaban por bancas indiscriminadamente niños y niñas. La diferencia se establecía por el nivel del curso. La maestra Amparo siempre atendió tres cursos. En casos excepcionales recibía para cuarto grado. En los tres cursos enseñaba ella sola y en promedio atendió sesenta alumnos ${ }^{74}$. Utilizó el método Lancasteriano de seleccionar a los alumnos más aventajados para colaborar en la enseñanza de los niños más pequeños. Reiteramos que los niños aprendían a escribir sobre pizarras con guiz.

Podríamos añadir que, contiguo al salón de clase, se localizaba la habitación de la maestra. Igualmente en tierra pisada, una cama organizada con los cuatro palos enterrados en el piso, y en un rincón un baúl donde se guardaba su ropa, la de la hija y la del "sobrino" que le acompañó por cuatro años, hasta finalizar el cuarto grado de primaria.

El hecho es de sobra conocido que las maestras llevaban un libro de matrícula de sus estudiantes. Se realizaba cada mes una reunión con los padres de familia donde los niños recitaban poesías y resolvían problemas de matemáticas. Cada semana, en esta escuela, se realizaba la izada de bandera, donde se premiaba al niño y niña más "juiciosa y aplicada". El premio consistía en una bandera pequeña que se colocaba con un alfiler al lado izquierdo de la camisa. Al finalizar el año se les entregaba la libreta de calificaciones donde se ubicaban, en números de 1 a 5 , las notas. Al final se localizaba una línea de observaciones donde se indicaba: repetir o aprobó. Se aprobaba el primer año a quienes sabían leer y escribir y sumaban y restaban. Se aprobaba el segundo curso: si en matemáticas sabía multiplicar y dividir. Además, se detallaban los conocimientos básicos en sociales, gramática española con reglas de ortografía y se avanzaba en ciencias naturales. Se aprobaba el tercer curso, si en matemáticas sabían regla de tres, quebrados según Baldor, llevar una contabilidad, escribir

73 Debemos indicar que cuando la maestra se traslado en el año 1980 a Fusagasugá le acompañaron varias cajas de libros y cuadernos de sus apuntes.

74 Comenta la maestra que los niños eran retirados de la escuela bien por enfermedad o por que el padre los necesitaba para ayudar en los quehaceres del campo. 
cartas con perfecta ortografía, sociales y ciencias según una guía que le había dado el alcalde en Miraflores. En resumen se puede decir, que sus alumnos, que continuaron estudios en los colegios de Miraflores, como dice la maestra "pasaron sobrados el examen, para la prueba estaba su hija, que finalizó con ella el tercer grado y pasó a cuarto en el Colegio de Miraflores"75.

La principal diferencia con la escuela urbana es que en el pueblo se tenía un profesor para los niños y una maestra para las niñas. Por supuesto, en la escuela urbana el piso era tablado y se les pedía "útiles escolares". En la escuela rural, como se ha señalado, una maestra era para todos los cursos. Quizá, es allí donde sólo se cumple esta característica de la escuela unitaria, dado que las seis restantes características quedaban sólo en el papel ${ }^{76}$.

El método utilizado por la maestra Amparo era el de la memoria. Este era el que había aprendido y el único sistema que consideraba que iba a funcionar, acompañado de la vara que traían los padres para cada hijo el día de la matrícula. Ahora, en la distancia considera que lo más difícil era hacer "callar los chinos". Cuando estaban muy inquietos los sacaba a todos al patio a educación física.

\section{El comercio, la iglesia, las fiestas. Punto de encuentro del campo y la ciudad}

Las reuniones en el campo se realizaban por un entierro, una molienda o un matrimonio principalmente. En los entierros se servía comida durante los nueve días, a la gente que llegara acompañar el "rezo" de la novena. En las moliendas de caña, se dejaba un día para realizar la melcocha y el alfondoque. Las reuniones que organizaba la maestra consistían en bazares en la escuela, con el objeto de recoger fondos para la misma escuela. En estos bazares cada familia traía una comida para la venta. Se cantaba y tocaba música bailable. También convocaba a una reunión mensual, con izada de bandera, donde se presentaba el informe académico y de conducta de cada alumno.

Por otra parte, debemos decir, que el punto de encuentro entre la población campesina y la del pueblo se establecía a través varios espacios. En primer lugar, el comercial. En el mercado de los domingos y de los jueves, que se realizaba en la plaza central del pueblo de Yacopí y en los almacenes de ropa ${ }^{77}$ y de víveres. Precisamente el mercado es considerado como uno de

5 Entrevista a Arango, Amparo y la hija, Bogotá, 7 de enero del 2009.

76 La Escuela Unitaria se inicia en 1961 cuando la UNESCO patrocinó la conferencia Internacional de Ministros de Educación en Ginebra, Suiza.

77 En la entrevista a Arango, Emira, Bogotá, 20 de agosto del 2012, quien nos describe los almacenes de telas: el de Tulio Cárdenas, Marcelino Pineda, Daniel Infante, Pedro Vanegas y el Sr. Sánchez. 
los sitios de sociabilidad entre lo urbano y lo rural. Allí se mezclan todos los grupos sociales ${ }^{78}$. Igual situación se vivía en el mercado de los pueblos donde trabajó Amparo en Boyacá. Allí se mezclaba el trueque y la venta según el producto y las circunstancias del momento.

El segundo espacio es el religioso, característico para el encuentro social en Cundinamarca y Boyacá. Los pueblos de esta región presentan prácticas religiosas similares y con un gran respeto por el sacerdote. La iglesia, no era sólo para la misa. Era el lugar donde, sin decir nombres, el sacerdote ventilaba los problemas del momento y con frecuencia tomaban posición de apoyo a un partido político.

El tercer espacio es el de las festividades religiosas, patrias y civiles o las comúnmente denominadas fiestas del pueblo. Desde luego, las fiestas que más recuerda Amparo, en su infancia, son las de diciembre, como las "fiestas del pueblo". Esta fiesta era especial. Iniciaba con las bandas de música que tocaban desde las seis de la mañana. Se tenían corridas de toros, cabalgatas y carreras de caballos. Era la ocasión para vender y comprar el ganado vacuno y los caballos. La plaza central se llenaba de kioscos de venta de cerveza y "cachivaches". La novena de aguinaldo se realizaba a lo vivo. Amparo se vestía de virgen, y sus hermanas, Emira y Mariela, de ángeles. San José durante varios años fue Useche. El niño Dios se fue turnando por cada Arango: Euclides y Enrique. Pero sin lugar a dudas el personaje central de la fiesta, era el padre español Gerardo Bilbao, cura párroco que bautizó y casó a esta generación, que nació en Yacopí y vivió la época de la violencia de mediados del siglo XX, Pero el hecho es que para los conservadores era el "curita cachiporro o curita chusmero"79.

Desde luego, en las festividades no era menos importante la Semana Santa. Precisamente, el viernes santo, los campesinos del municipio de Yacopí traían árboles, que introducían en la iglesia. A las tres de la tarde, se escuchaban tres matracazos que parecían disparos y algunos feligreses movían con fuerza los árboles, para representar la narración de los evangelios, donde se afirma que en el momento que Jesucristo expiró la tierra tembló, hubo un eclipse del sol y se rasgo el velo del templo. Como hemos señalado en otros estudios, recuerda Amparo que ya en su ejercicio laboral en la Semana Santa, el cura párroco en el sermón preguntaba a los feligreses “¿Quien mató a Jesucristo? y los hacía repetir: los liberales" $"$.

Gonzalbo, "Vida cotidiana",188.

79 Emira comenta que ella regreso sólo al pueblo en los años sesenta a las bodas de oro del padre Bilbao Entrevista en Bogotá el 19 de agosto del 2012. Véase comentarios sobre el padre Bilbao en Alirio Bustos Valencia. Sobrevivientes de la tempestad. (Bogotá: Círculo de lectores, 1998), 24.

80 Se refiere a la población de Siachoque en Boyacá. Entrevista a Arango, Amparo, Fusagasugá, 15 de noviembre del año 2004. En la fiesta de cumpleaños. Filmada. 
No se trata aquí de un estudio de las fiestas que vivió la maestra en su desempeño docente. Sólo destacamos que era obligatoria su presencia en las fiestas religiosas y las patrias. En la vereda del Guamal le correspondía viajar al caserío de Páez. Allí se celebraba el 20 de julio, que consistía en una concentración de los escolares en la plaza principal y desde el atrio de la iglesia hablaban las autoridades del municipio y luego se realizaban bailes, cantos coplas por parte de los niños y niñas. Cada escuela debería presentar una actividad. En las primeras comuniones toda la actividad se realizaba en la iglesia. Era muy importante la vela blanca y las niñas se vestían de blanco y los niños con su uniforme oscuro. En el viernes santo se realizaba procesión y luego se escuchaba el sermón dentro de la iglesia.

\section{CONCLUSIÓN}

Retomando nuestra pregunta inicial de este estudio, nos ha llevado a concluir que desde la época de inicio del estudio se presenta un desplazamiento de un grupo social de zonas rurales y de pueblos que emigraron hacía las ciudades capitales y a otras regiones en el país. Dentro éste grupo destacamos a las mujeres que la violencia desaloja de sus regiones de origen y las lleva a vincularse al magisterio como medio de supervivencia. Este es el caso de la joven Amparo, liberal por tradición familiar y proveniente de un pueblo con el $99 \%$ de su población liberal. Hay que decir, que ella sale de su región en desplazamiento forzado, que al igual que a miles de compatriotas esta situación les genero cambios en las relaciones socio-económicas donde la educación fue el principal elemento en esta superación personal. Por otra parte, las secuelas de la violencia estuvieron presentes en la maestra donde con una capacidad de adaptación desarrolló actividades socio-educativas, en las escuelas rurales donde realizó su desempeño docente, como ella comenta, con vocación y amor a su comunidad.

Pero si hubiera que subrayar lo más significativo, de la experiencia de vida de Amparo, entre sus primeros 23 años de vida urbana contrastada con los 27 de vida rural en Boyacá, debemos referirnos, en primera instancia, a este período histórico donde las costumbres de lo cotidiano varían drásticamente. En la alimentación, ingresan nuevos alimentos de la ciudad al campo sin variar en lo fundamental la dieta alimenticia; las formas de construcción cambian del bareque al adobe y más adelante al ladrillo. Los tejados evolucionaron del palmiche a la teja de zinc. El vestido de la mujer se transforma y en las nuevas generaciones se pasa de la falda larga a la minifalda y el pantalón en las mujeres. Los muchachos dejan la ruana y el sombrero que se cambia por la gorra. Del "pie limpio", en el campo, se pasa a la bota de caucho. Las mujeres adolescentes en los años 70 emigran al pueblo y a la capital como empleadas 
domésticas o para estudiar, dando una apertura respecto a la función social de la mujer, cuando ésta se vincula al ciclo de la educación. En estricto sentido los cambios en el medio rural se acompañaron de los cambios políticos, de tenencia de la tierra, junto al impacto de nuevas costumbres urbanas, que afectaron las relaciones sociales y las costumbres, difíciles de mantener al transformarse la estructura rígida, de la autoridad paterna, en las familias rurales. Las escuelas se modernizan en las instalaciones más por trabajo de la comunidad que por política del Estado, que no logra transformar en este período la escuela unitaria, en métodos de aprendizaje.

Pero sin lugar a dudas destacamos en este estudio a una mujer, liberal, separada y cabeza de familia, que se desempeñó como maestra de escuela rural, demostrando capacidad de inserción en los nuevos contextos sociopolítico-culturales, donde desplegó los valores humanos de solidaridad y de tolerancia con una labor educativa que traspasó las relaciones de enseñanzaaprendizaje, para un impacto social local, con su ejemplo de vida. El cambio de mentalidad, respecto a la educación de la mujer, generó escasos resultados por los imaginarios patriarcales dominantes de la época. Sin embargo, los cambios en la educación de la mujer surgieron por los medios de comunicación y transformaciones de los imaginarios socio-culturales. Finalmente, destacamos la añoranza de todos los entrevistados en la búsqueda de sus raíces como un eslabón perdido en el pueblo de paz que les fue quemado y bombardeado, en diciembre de 1952, pero reconociendo que la educación fue el factor de progreso predominante en sus cambios de vida.

\section{FUENTES}

\section{Entrevistas a:}

Arango Linares, Euclides, Fusagasugá, 6 de marzo y 15 de noviembre del 2004. (Actualmente de 71 años). Hermano de amparo y ahijado de Andrea.

Arango Linares, Emira, Bogotá, 31 enero, 18 febrero, 6 marzo del 2011, 29 Julio y 18 agosto del 2012. (Actualmente de 83 años. Hermana de Amparo).

Arango Linares, Mariela, Bogotá, 31 enero, 18 febrero, 6 marzo del 2011, 29 Julio y 18 agosto del 2012. (Hermana de Amparo Arango. Actualmente de 79 años).

Arango Cifuentes, Ulises, Bogotá 29 diciembre 2009, Bogotá, 31 diciembre 2010 y por teléfono 28 de marzo del 2012. (Actualmente con 71 años. Sobrino de Amparo).

Arango Cifuentes, Germán, Bogotá, 13 de marzo del 2011. (Actualmente con 69 años. Sobrino de Amparo y ahijado de Andrea).

Cifuentes, Yolanda, Bogotá, 19 de diciembre del 2009, 14 febrero del 2011. (Nació en 1927. Amiga de Yacopí. Edad actual 79 años. Amigo de Arcabuco.

Casas, Carmenza, Bogotá 17 y 22 de febrero del 2011. (Hija de Tulia).

Eloísa Penélope Rubio. Hija de Andrea. Entrevista en Bogotá el 6 de Enero, 12 febrero y 14 marzo del 2011. 
Hija de Amparo. Bogotá, Marzo del 2009, marzo del 2011.

Arango Rincón, Amparo, filmadas en Fusagasugá, 15 noviembre del 2004. Transcritas 15 noviembre 2008, Bogotá, 6 y 7 de enero 2009, Bogotá, 2 enero, Fusagasugá, 15 febrero 2011, 10 mayo 2011; Fusagasugá, julio y agosto del 2012.

Campos Arango, María Eugenia, Bogotá, febrero, marzo del 2011. (Sobrina de Amparo. Viajó a la vereda de Tunjita).

Ayala, Yaneth, Tunja, 21 de febrero, 18 de marzo del 2011. (Nieta).

Vargas Arango, Rosalía, Bogotá, 13 de febrero del 2011. (Sobrina de Amparo que vivió en la Escuela de Siachoque con su tía.)

Rodríguez, Ana y Rodríguez, Elisa, Fusagasugá, 22 de febrero del 2011. (Ex alumnas de la Escuela de Morro Arriba.

Hernández de Casallas, Leonor, Vicente y Hortensia Casallas, Fusagasugá, 13 de marzo del 2011. (Amigos).

Murcia, Víctor, Fusagasugá, 15 de noviembre 2011 y 12, 19, 26 de agosto del 2012. (Amigo de Yacopí y La Palma. Actualmente, vive en Fusagasugá).

Archivo Personal Diana Soto Arango. Fondo Maestras, Sección Arango, Amparo.

Archivo Familiar de Eloísa Rubio.

Archivo Juzgado Promiscuo de Rondón.

Texto de la época: Cartilla Charry; Urbanidad de Carreño, Catecismo Padre Astete; Diccionario ortográfico, Algebra de Baldor.

Legislación

Decreto 1340 del 30 de julio de 1941; Decreto 2294, 31 diciembre, Art. 17 y 18, salarios; Decretos 2838 de 1954; Ley 143 de 1938; Ley 1 de 1961; Decreto 2956 de 1955.

\section{REFERENCIAS}

\section{Metodología}

Gonzalbo, Pilar. Vida cotidiana. México: Colegio de México, 2006.

\section{Escuelas y la ruralidad}

Alarcón de Ortega. (1955): La Educación Rural y la Educación Fundamental en Colombia. Centro Regional de Educación Fundamental para la América Latina. http:/ /www.crefal.edu.mx/biblioteca_ digital/coleccion_crefal/tesis/alarcon_ortega. df. (16 marzo 2012).

Angulo h, Ligia, Morera H, David y Torres V, Nancy. "Modelo y práctica pedagógica en la escuela rural unidocente y multigrado centroamericana: condiciones, limitaciones y potencialidades", en PATRIA GRANDE Revista Centroamericana de Educación (2009) bttp:// www.ceducar.info/OJS. (16 de marzo de 2012).

CIDER-Centro Interdisiplinario de Investigaciones sobre Desarrollo. La nueva ruralidad. Serie documentos conceptuales. Bogotá: Universidad de Los Andes, 2000.

Ramírez G, María y Téllez C, Juana. La educación primaria y secundaria en Colombia en el siglo XX. . Bogotá, 2006). http://www.banrep.gov.co/docum/ftp/borra379.pdf. (16 de marzo de 2012).

Ramón Suárez, Josué. Historia y sentido de la escuela rural. De la escuela unitaria a la educación media. 1960-2005. Tesis doctoral. Doctorado Ciencias de la Educación. Tunja, Universidad Pedagógica y Tecnológica de Colombia. RUDECOLOMBIA, 2006. 
Sauras, J. Espejo, M. Trabajar en la Escuela Rural. Madrid: Federación de movimientos de Renovación Pedagógica MRP, 1998.

Soto Arango, Diana. "Historias de vida de dos maestras de escuela de mediados del siglo XX en Colombia. Amparo y Andrea. Liberal y conservadora en contextos de la ruralidad educativa cundí-boyacense”, editado por: Diana Soto, Jesús Paniagua, José Rubens Lima Jardilino y María Cristina Vera de Flachs. Tunja: Ediciones Doce Calles, 2011, 365-368.

Teubal, M. "Globalización y nueva Ruralidad en América Latina”, en Una Nueva Ruralidad en América Latina. (Bogotá: Editorial Uniandes, 2005).

Teubal, M. "Globalización y nueva Ruralidad en América Latina”. (2005). http//: www.clacso. org/. consultado 28 abril del 2012

Triana, Alba Nidia. "Historia de la educación rural en Colombia. 1946-1994". Tesis Doctoral en, Doctorado en Ciencias de la Educación. Universidad Pedagógica y Tecnológica de ColombiaRUDECOLOMBIA, 2010.

Wulf, Christoph. "¿Cómo adquiere sentido la Escuela? Encuentros Pedagógicos Transculturales". Medellín: Universidad de Antioquia, Facultad de Educación, 2001.

\section{Educación femenina. Maestras y escuelas rurales}

Bellucci, Mabel. "Mujeres en la educación: género y docencia en Argentina: 1870-1930. Buenos Aires.

Ferro, Myriam Stella. "Mi vida. Historia de la vida de una maestra rural colombiana". Bogotá: Editorial Guadalupe, 1978.

Hamon, Ana. "Ingreso de la mujer docente a la UPTC 1961-1980". Tesis Doctoral en Doctorado Ciencias de la Educación, Universidad Pedagógica y Tecnológica de ColombiaRUDECOLOMBIA, 2010.

Hernández de Alba, Guillermo. "Galería de ilustres educadoras colombianas [manuscrito]: en 1. Colegio de La Merced. Bogotá: Edit. Kelly, 1980

Sánchez de Serdio Aida, "Traducido" en Ivor F, Goodson, "Historias de vida del Profesorado. Trad. Sánchez de Serdio Aida, (Barcelona: Octaedro editorial, 2004)

King, Elizabeth. "Educating girls and women: investment in development". Washington: World Bank, 1990.

Mistral, Gabriela. "Nubes blancas (poesías) y la oración de la maestra". Barcelona: Editorial B. Bauza, 1941.

Vera de Flachs, María Cristina. "De comadronas a obstetras. La institutionalization del saber". Córdoba: Báez Ediciones, 2010.

Woods, P. "Life Histories and Teacher knowledges, en educating teachers; changing the nature of pedagogical knowledges". Londres, Filadelfia y New York: falmer, 1987.

Pérez Peláez, Liria. 'La educadora de primaria: autopercepción de sus roles como maestra y mujer". Medellín: Universidad de Antioquia- Facultad de Educación, 1990.

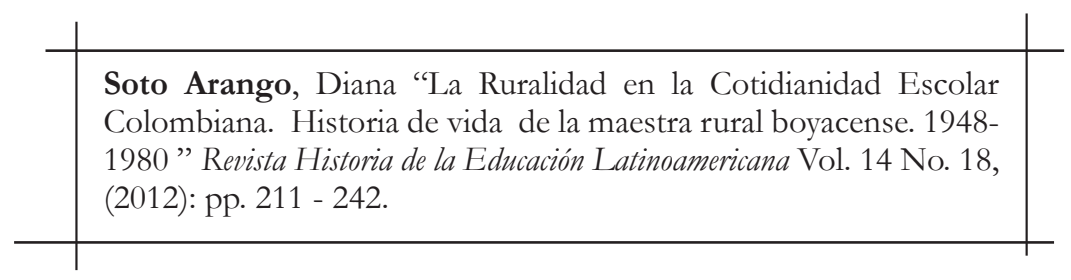

